\title{
Physicochemical and Morphological Characterization of Potato Starch Modified by Bacterial Amylases for Food Industry Applications
}

\author{
Adel Vafina, ${ }^{1}$ Victoria Proskurina, ${ }^{2}$ Vyacheslav Vorobiev, ${ }^{3}$ Vladimir G. Evtugin, ${ }^{3}$ \\ Galina Egkova, ${ }^{1}$ and Elena Nikitina $\mathbb{C}^{1,4}$ \\ ${ }^{1}$ Institute of Food Technology and Biotechnology, Department of Meat and Milk Technologies, \\ Kazan National Research Technological University, K. Marks Str. 68, Kazan 420015, Russia \\ ${ }^{2}$ Department of Physical and Colloid Chemistry, Kazan National Research Technological University, K. Marks Str. 68, \\ Kazan 420061, Russia \\ ${ }^{3}$ Kazan Federal University, Interdisciplinary Center for Analytical Microscopy, Kazan 420008, Russia \\ ${ }^{4}$ Kazan Federal University, REC Pharmacy, Kremlyovskaya 18, Kazan 420008, Russia \\ Correspondence should be addressed to Elena Nikitina; ev-nikitina@inbox.ru
}

Received 23 July 2018; Accepted 15 October 2018; Published 8 November 2018

Academic Editor: Carola Esposito Corcione

Copyright (C) 2018 Adel Vafina et al. This is an open access article distributed under the Creative Commons Attribution License, which permits unrestricted use, distribution, and reproduction in any medium, provided the original work is properly cited.

\begin{abstract}
Two multienzyme bacterial preparations of $\alpha$-amylase of Bacillus licheniformis and Amylosubtilin ${ }^{\circledR}$ were used in order to modify potato starch at various enzyme concentrations. Eight types of starch were obtained, and their morphological, functional, and physical and chemical characteristics were studied. Induction of enzyme preparations allowed obtaining starches characterized by extended solubility and water-sorption ability and also lower gelation temperatures and viscosity. It was found that studied amylolytic preparations do have different effects on starch granules, despite the identical major amylase activities. The combination of the characteristics studied in the enzymatically modified starches makes them promising for the use as a component of food systems requiring the corrections of their textural features.
\end{abstract}

\section{Introduction}

In the modern food industry, some functional food additives are commonly used, including modified starches that have high moisture-retention ability and provide the end product with the desired textures and consistencies. Each food additive has its own advantages and disadvantages, knowing them allow us to achieve the best results in using such additives in specific processing conditions.

Potato, corn, wheat, rice, tapioca, and some other starches are used to obtain modified starches. The starches are processed using physical, chemical, or enzymatic methods during the treatment $[1,2]$.

Differences in the properties of starches are manifested in accordance with the source and genotype. The starch properties mainly depend on their physical and chemical characteristics, the average granule sizes, the percentage of distribution of the differently sized groups of granules, the amylose/amylopectin ratio, and their mineral contents [3]. Starch granule' forms and sizes are the characteristics of their botanical origin. The granules' form may vary from absolutely spherical and rounded to oval $[4,5]$.

By changes taking place in native starches, five main modifications can be highlighted: pregelatinization, depolymerization, oxidation, stabilization (without crosslinking polymeric chains), and formation of cross-linked starches [1].

Potato starch is one of the most common polysaccharides used as thickeners and stabilizer in food systems. Potato starch historically has been most widely used in sausage manufacturing, mostly due to its low gelatinization temperature. Considering that pasteurizing the sausages 
takes place at a relatively low temperature $\left(70-72^{\circ} \mathrm{C}\right)$, there is always a risk that the granules of any other starch would be unable to gelatinate in such conditions and efficiently bind water [6]. For potato starch, the difference in the granulated structure of starch from one sort to another is much higher. It was found that, in potatoes, the starch granule sizes are in a wide range, from several microns in diameter for small granules to $110 \mu \mathrm{m}$ for large ones [7].

Studies of different fractions of potato starches of different sorts have shown a general rule for amylose contents: the highest amylose concentration was found in the fraction with high molecular granules, while the lower one was found in the fraction with medium molecular granules, and the lowest one is one with low molecular granules [8]. A similar trend was found in the analysis of the gelatinization abilities of the fractions and the viscosity indexes.

It is well known that the gelling property of high and low molecular starch granules obtained from different potato sorts has different temperature profiles for gelatinization [9]. The fraction of small-sized starch granules has higher phosphor content than larger granules [10,11]. Physical and chemical properties, such as light transmission, amylose content, swelling power, and water-sorption ability, are highly correlated with the average granule sizes of starches extracted from different sorts of potatoes $[12,13]$.

Alongside with the abilities to gelling and swell, it is also important for the starches used in food industry to be able to retain water within the entire pasteurization process and the desired shelf life. This is actually an unreal task for native potato starch. However, it can be solved with the use of modified starches. Modified starches with different gelatinization temperatures can be used both in low-temperature processes, such as sausage pasteurization, and in sterilization processes, such as sterilization of canned meat. Since the biological modification is so promising in this case and it is necessary to obtain a safe product, potato starch was modified with two multienzyme bacterial preparations with leading amylase activity. Physicochemical, functional, processing, and morphological parameters of the starches were studied.

\section{Materials and Methods}

\subsection{Enzyme Preparations}

2.1.1. Obtaining the $\alpha$-Amylase Preparation of Bacillus licheniformis. We use a medium optimized for synthesis of $\alpha$-amylase: corn flour: $8 \%$; wheat flour: $8 \%$; feeding yeast: $3 \% ; \mathrm{MgSO}_{4} \times 7 \mathrm{H}_{2} \mathrm{O}: 0.2 \%$; and $\mathrm{CaCO}_{3}: 0.25 \%$. The $\mathrm{pH}$ of the medium before sterilization was set as 8.0-8.2. The strain was cultivated in $750 \mathrm{ml}$ flasks with $30 \mathrm{ml}$ of fermentation medium in a shaker $(240 \mathrm{rpm})$ at $37-43^{\circ} \mathrm{C}$ for $48-144 \mathrm{~h}$. The preparation was obtained by separation of biomass of the producer cells from the fermentation broth, using centrifuging at $8,000 \mathrm{rpm}$ for $10 \mathrm{~min}$. In the fermentation broth, the $\alpha$-amylase activity was $250 \mathrm{U} / \mathrm{ml}$ at $40^{\circ} \mathrm{C}$.

Amylosubtilin ${ }^{\circledR}$ (Berdsk Factory of Biological Preparations (now Sibbiofarm), Russia) is obtained by drying the fermentation broth upon the in-depth cultivation of Bacillus subtilis. It is a homogenous hygroscopic, water-soluble light beige or light gray powder. Amylosubtilin G3X consists of the following enzymes: $\alpha$-amylase: $1,000-1,600 \mathrm{U} / \mathrm{g}$, glucoamylase: up to $100 \mathrm{U} / \mathrm{g}, \beta$-glucanase: up to $500 \mathrm{U} / \mathrm{g}$, cellulase: up to $30 \mathrm{U} / \mathrm{g}$, xylanase: up to $10 \mathrm{U} / \mathrm{g}$, and neutral protease: up to $20 \mathrm{U} / \mathrm{g}$. Its amylolytic activity is $1,000 \mathrm{U} / \mathrm{g}$. Optimal conditions for its activities are as follows: $\mathrm{pH}=4.5-7.0$ and temperatures of $30-50^{\circ} \mathrm{C}$.

2.1.2. Detecting Amylase Activity. A volume of $0.5 \mathrm{ml}$ of the substrate $\left(1 \%\right.$ of soluble starch in the acetate buffer) at $50^{\circ} \mathrm{C}$ was added into the test tube containing $0.5 \mathrm{ml}$ of the enzyme (fermentation broth) for 30 minutes. Then, $450 \mu \mathrm{l}$ of 3,5dinitrosalycylic acid (DNSA) (an inhibitor removal buffer) was added. $0.5 \mathrm{~g}$ of the inhibitor removal buffer was prepared. DNSA was dissolved in $30 \mathrm{ml}$ of $\mathrm{H}_{2} \mathrm{O}$ at $50^{\circ} \mathrm{C}$, adding $5 \mathrm{ml}$ of the $\mathrm{Na}$ and $\mathrm{K}$ solution $(8 \mathrm{~g}$ of $\mathrm{NaOH}+11.2 \mathrm{~g}$ of $\mathrm{KOH}$, dissolved in $50 \mathrm{ml}$ of $\mathrm{H}_{2} \mathrm{O}$ ) and $5 \mathrm{ml}$ of solution ( $15 \mathrm{~g}$ of $\mathrm{Na}, \mathrm{K}$ tartrate in $50 \mathrm{ml}$ of $\mathrm{H}_{2} \mathrm{O}$ ). The mixture was incubated in the boiling water bath at $100^{\circ} \mathrm{C}$ for 5 minutes and cooled at $0^{\circ} \mathrm{C}$ for 5 minutes. $4.5 \mathrm{ml}$ of distilled was added. The sample was then measured at $540 \mathrm{~nm}$. The reference sample was prepared as follows: reference test tubes containing $0.5 \mathrm{ml}$ of the substrate ( $1 \%$ of soluble starch in the acetate buffer) was incubated at $50^{\circ} \mathrm{C}$ for 30 minutes. $450 \mu \mathrm{l}$ of DNSA (inhibitor removal buffer) was added. Then, $0.5 \mathrm{ml}$ of fermentation broth was added, incubated on the boiling water bath at $100^{\circ} \mathrm{C}$ for 5 minutes, and cooled at $0^{\circ} \mathrm{C}$ for 5 minutes. Then, $4.5 \mathrm{ml}$ of distilled $\mathrm{H}_{2} \mathrm{O}$ was added. The result was assessed using a calibration curve of reducing sugars (glucose).

2.2. Starch Modification. Native potato starch (according to GOST P52791-2007 standard) was used for the experiment. Modification of this starch was based on the application of Amylosubtilin ${ }^{\circledR}$ (AM) and amylase from Bacillus licheniformis (Bl) of different concentrations (Table 1). Modification was carried out in water $(30 \mathrm{~g} / 100 \mathrm{ml}), \mathrm{pH}=7$, $40^{\circ} \mathrm{C}$ for 1 hour. The hydrolysis reaction was stopped with the addition of concentrated sulfuric acid $(\mathrm{pH}=2)$. The starch was afterwards separated from the liquid by filtration and dried at $40^{\circ} \mathrm{C}$. The starches were used for further research.

2.3. Analysis of Physicochemical Properties of Starches. Amylose content was determined by the iodine binding method described by Williams et al. [14]. The amount of protein was measured using the method described by Bradford [15]. The Residual reducing sugar determination was analyzed using the 3,5-dinitrosalicylic acid (DNS) method [16]. The moisture of starch was determined by drying it at $105^{\circ} \mathrm{C}$, for $2 \mathrm{~h}$.

Water absorption capacity (WAC) and water solubility index (WSI) were described by Omojola et al. [17], which are used to determine the WAC and WSI. The starch sample (5\% $\mathrm{w} / \mathrm{v}$ ) was dispersed in a preweighed centrifuge tube. The tube was placed in a vortex mixer for $2 \mathrm{~min}$, left at room temperature for 30 minutes, gently stirred during this period, 
TABLE 1: Code of fermented modified starches.

\begin{tabular}{lccc}
\hline Starches & $\begin{array}{c}\text { Amylase } \\
\text { activity } \\
\text { (U/g starch) }\end{array}$ & $\begin{array}{c}\text { Amylosubthilin } \\
\text { (g/100 ml } \\
\text { reaction mixture) }\end{array}$ & $\begin{array}{c}\text { Amylase Bacillus } \\
\text { licheniformis } \\
\text { (ml/100 ml } \\
\text { reaction mixture) }\end{array}$ \\
\hline AM-0.05 & 0.415 & 0.01 & - \\
AM-0.1 & 0.83 & 0.0201 & - \\
AM-0.05 & 4.15 & 0.1005 & - \\
AM-1 & 8.3 & 0.201 & - \\
Bl-0.05 & 0.415 & - & 0.05 \\
Bl-0.1 & 0.83 & - & 0.1 \\
Bl-0.5 & 4.15 & - & 0.5 \\
Bl-1 & 8.3 & - & 1 \\
\hline
\end{tabular}

and then centrifuged at $3000 \mathrm{rpm}$ for 15 minutes. The supernatant was then discarded, and the weight of the tube and hydrated sample was measured. The weight was calculated and expressed as the weight of water bound by $100 \mathrm{~g}$ dry starch.

Water Solubility Index [17] determines the amount of polysaccharides or polysaccharide release from the granule on the addition of excess of water. WSI was the weight of dry solids in the supernatant from the WAC test. The supernatant liquid was then decanted into a tared evaporating dish of known weight. The weight of dried solid after evaporation in an air-circulating oven at $103^{\circ} \mathrm{C}$ was recorded. The WSI (expressed as grams solids/100 g of starch) was calculated from the weight of dry solids recovered by evaporating the supernatant at $110^{\circ} \mathrm{C}$ for $12 \mathrm{~h}$. Determinations were made in triplicate.

Gelatinization temperature was evaluated using the method of Attama et al. [18]. The starch sample $(1 \mathrm{~g})$ was put in a $20 \mathrm{ml}$ beaker, and $10 \mathrm{ml}$ of distilled water was added. The dispersion was heated on a hot plate. The gelatinization temperature was then measured with a thermometer suspended in the starch slurry.

2.3.1. Dynamic Viscosity. Viscosity was evaluated for the $1 \%$ starch solution, pregelatinized, and cooled down to $20^{\circ} \mathrm{C}$, using the VNZh (Russia) glass capillary viscosity meter, tracking the starch gel flow time.

\subsection{Granule Morphology and Size}

2.4.1. Optical Microscopy. The morphology of the starch suspensions was studied using a light microscope Axio Imager.Z2m (Carl Zeiss). A thin layer of the paste was prepared on a slide and stained with iodine solution. The granules were photographed using a Nikon camera attached to the microscope.

2.4.2. Scanning Electron Microscopy (SEM). Starch samples were mounted on metal stubs and coated with goldpalladium alloy ( $\sim 15 \mathrm{~nm}$ thickness) using the Quorum Q150T ES vacuum coating machine. Samples were then observed using a field emission scanning electron microscope Merlin (Carl Zeiss, Germany) at an acceleration potential of $15 \mathrm{kV}$, secondary electrons detector. Pictures were captured by automatic image capturing software (Hitachi High-Technologies, Pleasanton, CA). Magnifications are as indicated at the bottom of each figure.

The microimages obtained were used to detect any damage in starch granules and to define their forms.

2.4.3. Granule Size. The effect of enzymatic treatment on the size of starch was studied by dynamic light scattering (DLS) with a method using Zetasizer Nano-ZS series particle size and zeta potential analyzer (Malvern, the United Kingdom) at $25^{\circ} \mathrm{C}$. For this purpose, we prepared $0.5 \mathrm{~g} \cdot 1^{-1}$ solutions of starch in dimethylsulfoxidet. We determined the hydrodynamic radius $D_{\mathrm{h}}$ of the particles after $24 \mathrm{~h}$ of exposition at ambient temperature.

2.5. Thermal Gravimetric Analysis (TGA) and Differential Thermal Analysis (DTA). TG and DT curves were recorded using a simultaneous TG 60 system (Shimadzu) under an air flow at $100 \mathrm{~mL} \cdot \mathrm{min}^{-1}$ and at a heating rate of $10^{\circ} \mathrm{C} \cdot \mathrm{min}^{-1}$. The initial sample mass was about $9 \mathrm{mg}$. Alumina crucibles were used for the TG and DTA experiments.

\section{Results and Discussion}

3.1. Properties of Fermented Modified Potato Starches. The amylose percentage in the starch under the effect of the enzyme Amylosubtilin ${ }^{\circledR}$ decreases by $6-11 \%$, and the largest decrease is found for the samples treated with the highest or with the lowest enzyme concentration (Table 2). After treating with the amylase Bacillus licheniformis in starches, the relative amylose content increased by $1-3 \%$ in three samples and decreased by $6 \%$ in the starch treated with the highest concentration of the enzyme (Bl-1).

The content of free reducing sugars in all the test samples was higher than in the native starch. At the same time, this value was higher in the amylosubtilin-treated samples than in the samples treated with the amylase of B. licheniformis.

The protein contents in test samples were lower than in the source starch, which may have been resulted from the presence of proteases within the compositions of enzyme preparations. The residual moisture contents in the samples varied within the range of $9-11 \%$.

As a result of modification, the water absorption capacity practically doubled in amylosubtilin-treated starches, while the increase thereof in the $\mathrm{Bl}$ starches was lower. At the same time, after modification, the solubility of starches (WSI) increased, the highest WSI was for starches AM-0.1 and Bl-1 (Table 3).

Modification led to a significant decrease of the gelatinization temperature. In the AM starches, the increase of the enzyme concentration at the treatment led to obtaining of the starch with a lower gelatinization temperature. In case of increase of the concentration of the amylase of B. licheniformis when treated from the lowest to the highest, the increase of the gelatinization temperature was found in the starches obtained. 
TABle 2: Physical-chemical parameters of native and fermented modified potato starches.

\begin{tabular}{lccccc}
\hline Starch samples & Amylose (\%) & Amylopectin (\%) & Residual reducing sugar (g/g of starch) & Protein $(\mathrm{g} / 100 \mathrm{~g}$ of starch) & Moisture $(\%)$ \\
\hline Native & $24.99 \pm 1.22$ & $74.32 \pm 2.54$ & $0.69 \pm 0.25$ & $0.48 \pm 0.05$ & $10.22 \pm 1.02$ \\
AM-0.05 & $13.09 \pm 1.52$ & $85.47 \pm 1.27$ & $1.44 \pm 0.25$ & $0.15 \pm 0.09$ & $10.23 \pm 1.23$ \\
AM-0.1 & $17.83 \pm 2.15$ & $81.99 \pm 2.68$ & $0.78 \pm 0.09$ & $0.13 \pm 0.02$ & $9.78 \pm 2.05$ \\
AM-0.5 & $14.80 \pm 1.27$ & $84.28 \pm 1.89$ & $0.92 \pm 0.12$ & $0.12 \pm 0.03$ & $10.63 \pm 1.25$ \\
AM-1 & $13.00 \pm .2 .01$ & $86.01 \pm 0.98$ & $0.99 \pm 0.27$ & $0.24 \pm 0.59$ & $12.46 \pm 0.98$ \\
Bl-0.05 & $25.87 \pm 1.25$ & $72.90 \pm 1.25$ & $1.23 \pm 0.09$ & $0.44 \pm 0.08$ & $11.42 \pm 1.23$ \\
Bl-0.1 & $27.70 \pm 0.98$ & $71.29 \pm 0.98$ & $0.99 \pm 0.24$ & $0.12 \pm 0.05$ & $9.40 \pm 2.24$ \\
Bl-0.5 & $25.35 \pm 1.27$ & $73.44 \pm 0.26$ & $1.21 \pm 0.35$ & $0.19 \pm 0.08$ & $10.41 \pm 1.02$ \\
Bl-1 & $18.99 \pm 2.01$ & $79.40 \pm 2.01$ & $1.61 \pm 0.07$ & $0.43 \pm 0.03$ & $9.92 \pm 0.95$ \\
\hline
\end{tabular}

TABLE 3: Functional properties of native and fermented modified potato starches.

\begin{tabular}{lcccc}
\hline $\begin{array}{l}\text { Starch } \\
\text { samples }\end{array}$ & $\begin{array}{c}\text { WAC }(\mathrm{g} \\
\mathrm{H}_{2} \mathrm{O} / \mathrm{g} \\
\text { starch) }\end{array}$ & $\begin{array}{c}\text { WSI (g } \\
\text { solids/100g g } \\
\text { starch) }\end{array}$ & $\begin{array}{c}\text { Gelatinization } \\
\text { temperature } \\
\left({ }^{\circ} \mathrm{C}\right)\end{array}$ & $\begin{array}{c}\text { Dynamic } \\
\text { viscosity } \\
(\mathrm{sec})\end{array}$ \\
\hline Native & $1.37 \pm 0.11$ & $1.22 \pm 0.030$ & $69.0 \pm 0.9$ & $28.03 \pm 1.21$ \\
AM- & $2.14 \pm 0.12$ & $6.97 \pm 0.58$ & $61.5 \pm 1.2$ & $4.58 \pm 1.39$ \\
0.05 & & & & \\
AM-0.1 & $2.27 \pm 0.28$ & $8.64 \pm 0.24$ & $57.9 \pm 0.6$ & $3.44 \pm 1.38$ \\
AM-0.5 & $2.18 \pm 0.22$ & $5.30 \pm 0.59$ & $59.8 \pm 1.0$ & $3.96 \pm 1.66$ \\
AM-1 & $2.05 \pm 0.30$ & $2.79 \pm 0.64$ & $54.7 \pm 1.5$ & $4.55 \pm 1.82$ \\
Bl-0.05 & $2.08 \pm 0.14$ & $4.30 \pm 0.51$ & $55.1 \pm 2.1$ & $4.24 \pm 1.53$ \\
Bl-0.1 & $2.15 \pm 0.12$ & $3.38 \pm 0.25$ & $56.7 \pm 1.7$ & $4.11 \pm 0.98$ \\
Bl-0.5 & $1.97 \pm 0.08$ & $4.40 \pm 0.65$ & $57.6 \pm 1.3$ & $5.22 \pm 2.02$ \\
Bl-1 & $1.68 \pm 0.14$ & $7.39 \pm 0.29$ & $61.0 \pm 1.9$ & $4.69 \pm 1.09$ \\
\hline
\end{tabular}

\subsection{Granule Morphology}

3.2.1. Optic Microscopy. The native starch had kernels of a round regular shape with the small particles of starch granules with even, nondappled edges (Figure 1(a)).

Losing clear external boundaries and appearance of internal radial layers are characteristics for the starch modified by the lowest concentration of amylosubtilin (AM0.05). Doubling the concentration (sample AM-0.1) led to the decrease of the number of large granules and increase of the number of fission-induced irregular particles. Gelatinization of round kernels is the characteristic for samples AM-0.5 and AM-1, which resulted in the increase of the number of blurred irregular granules with dappled edges (Figure 1).

In the starch, modified with the B. licheniformis amylase, in the concentration of 0.05 , the external layers are not involved; however, a central groove occurs in the kernel. For the sample of Bl-0.1, the effects of the central cross and blurring granule boarders are pronounced stronger. Further increasing the concentration (Bl-0.5) led to a more marked manifestation of concentric circles, and both gelatinization of granules and blurring the boarders are observed. In sample Bl-1, the shape of granules become irregular with uneven edges, and the number of small granules increases (Figure 1).

3.3. Scanning Electron Microscopy. The native starch had kernels of round and regular shape, there were both large and small particles, and the granules had even, nondappled edges (Figure 2(a)). The loss of clean external boarders and the presence of grooves and notches are characteristics for the starch modified with the lowest concentration of amylosubtilin (AM-0.05). Doubling the concentration (sample $\mathrm{AM}-0.1$ ) led to the increase of the number of fission-induced irregular particles with multifaceted edges and to the decrease of the number of large granules, while the rest had uneven edges (Figure 2).

Gelatinization of kernels and breaking large granules into smaller ones with irregular shape with dappled edges and grooves are characteristics for samples AM-0.5 and AM- 1 .

In the starch, modified with the B. licheniformis amylase, with the concentration of 0.05 (the lowest one), the external layers became rough, the shape of granules did not change, and no visible grooves were observed. In sample $\mathrm{Bl}-0.1$, the increase of the number of smaller granules with uneven edges and the cracks on the surfaces was visible.

Further increase of concentration (Bl-0.5) led to the gelatinization, and the granules having uneven dappled edges became prevailing. The hydrolysis of external layers can be seen (cracks and grooves). In sample Bl-1, the granules have irregular shape with uneven edges; in some granules, splitting into layers and deshaping were observed (Figure 2).

3.4. Granule Size. Distribution of the macromolecules of the native starch in DMSO has bimodal nature, with the maximums of $R_{\mathrm{h}} 28$ and $68 \mathrm{~nm}$. At the same time, $67 \%$ of the total area under the peaks of the light scattering intensity distribution falls within the fraction of large particles (50$141 \mathrm{~nm})$. Such two fractions' distribution corresponds with the amylose-based and amylopectin-based parts of starch, the last one playing a key role in light scattering of starch solution (Figure 3).

Distribution of the hydrodynamic radii of the molecules of starches AM-0.05, Bl-0.05, and Bl-0.1 is also bimodal. At the same time, the modal values of the radii of starches $\mathrm{Bl}$ 0.05 and Bl-0.1 for the amylose fraction became lower: 4$7 \mathrm{~nm}$ and $5-8 \mathrm{~nm}$, respectively, while for the amylopectin fraction, it increased up to $80-182 \mathrm{~nm}$ and $91-209 \mathrm{~nm}$, respectively. The particle radii' values of the AM-0.05 starch are practically the same as the molecule sizes of the native starch: $29-50 \mathrm{~nm}$ for amylose and $66-100 \mathrm{~nm}$ for amylopectin. Moreover, the total content of this fraction significantly decreased. The molecule sizes of the amylopectin of AM-0.05 starch, as compared to the native one, became 


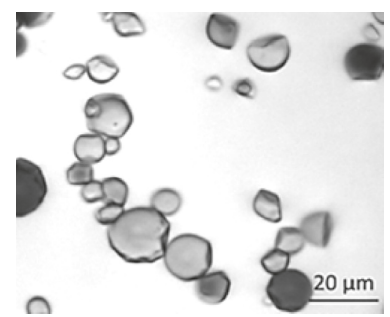

(a)<smiles>c1ccccc1</smiles>

08 0<smiles>C1=CC2CCCCCCCCC2C1</smiles><smiles></smiles>

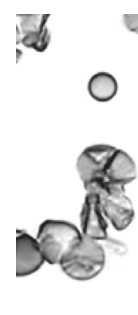

(b)

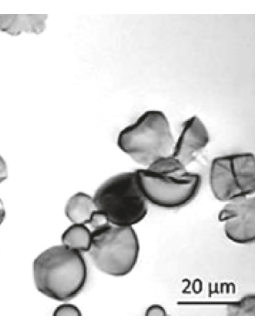

(b)

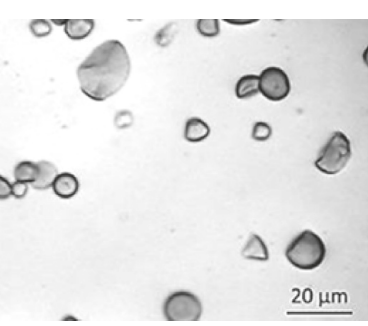

(c) (d)

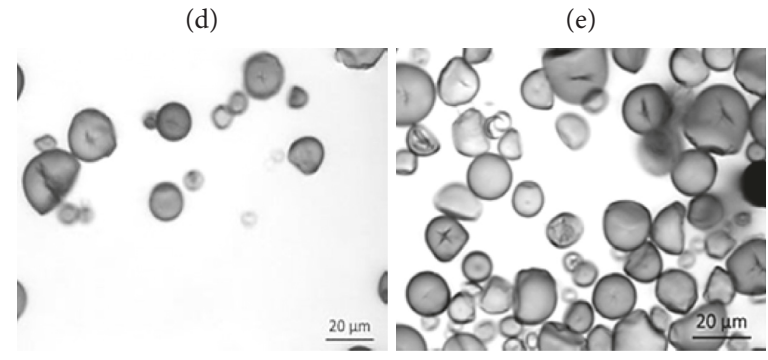

)

(h)

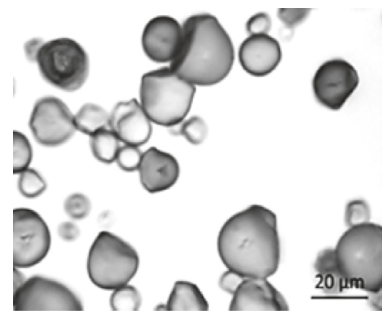

(f)

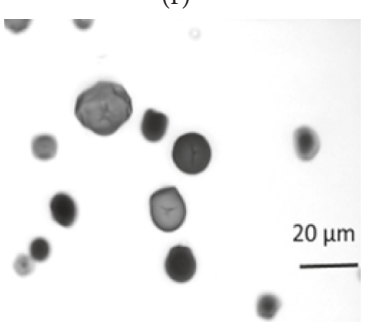

(i)

FIGURE 1: Optical microphotographs of native (a) and fermented modified potato starches (bar is $20 \mu \mathrm{m}$ ): (b) AM-0.05, (c) AM-0.1, (d) AM-0.5, (e) AM-1, (f) Bl-0.05, (g) Bl-0.1, (h) Bl-0.5, and (i) Bl-1.

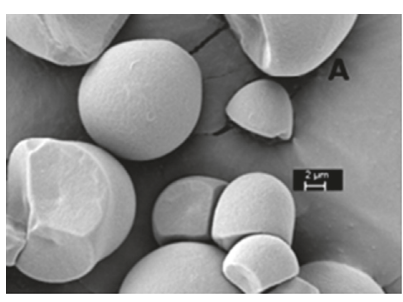

(a)

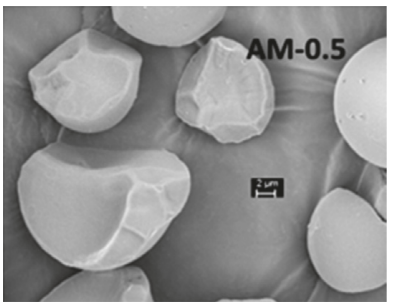

(d)

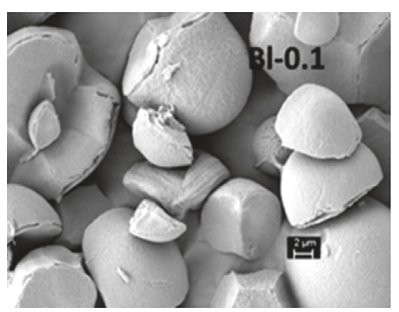

(g)

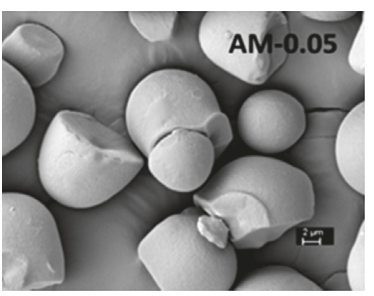

(b)

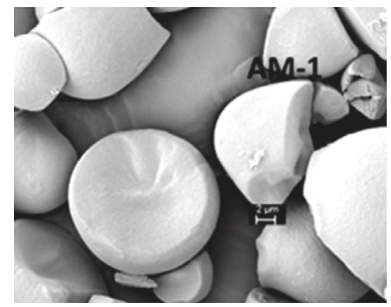

(e)

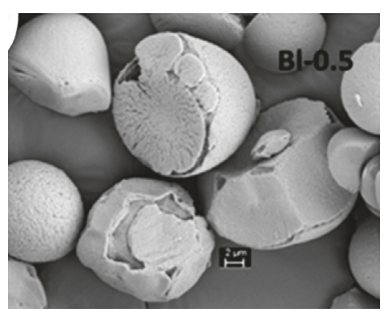

(h)

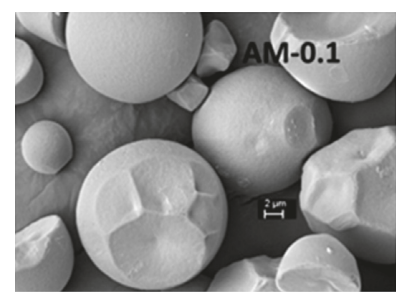

(c)

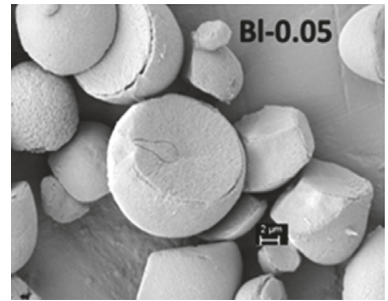

(f)

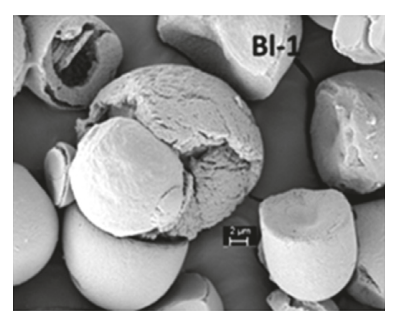

(i)

FIGURE 2: SEM microphotographs of native (a) and fermented modified potato starches (bar is $2 \mu \mathrm{m}$ ): (b) AM-0.05, (c) AM-0.1, (d) AM-0.5, (e) AM-1, (f) Bl-0.05, (g) Bl-0.1, (h) Bl-0.5, and (i) Bl-1. 

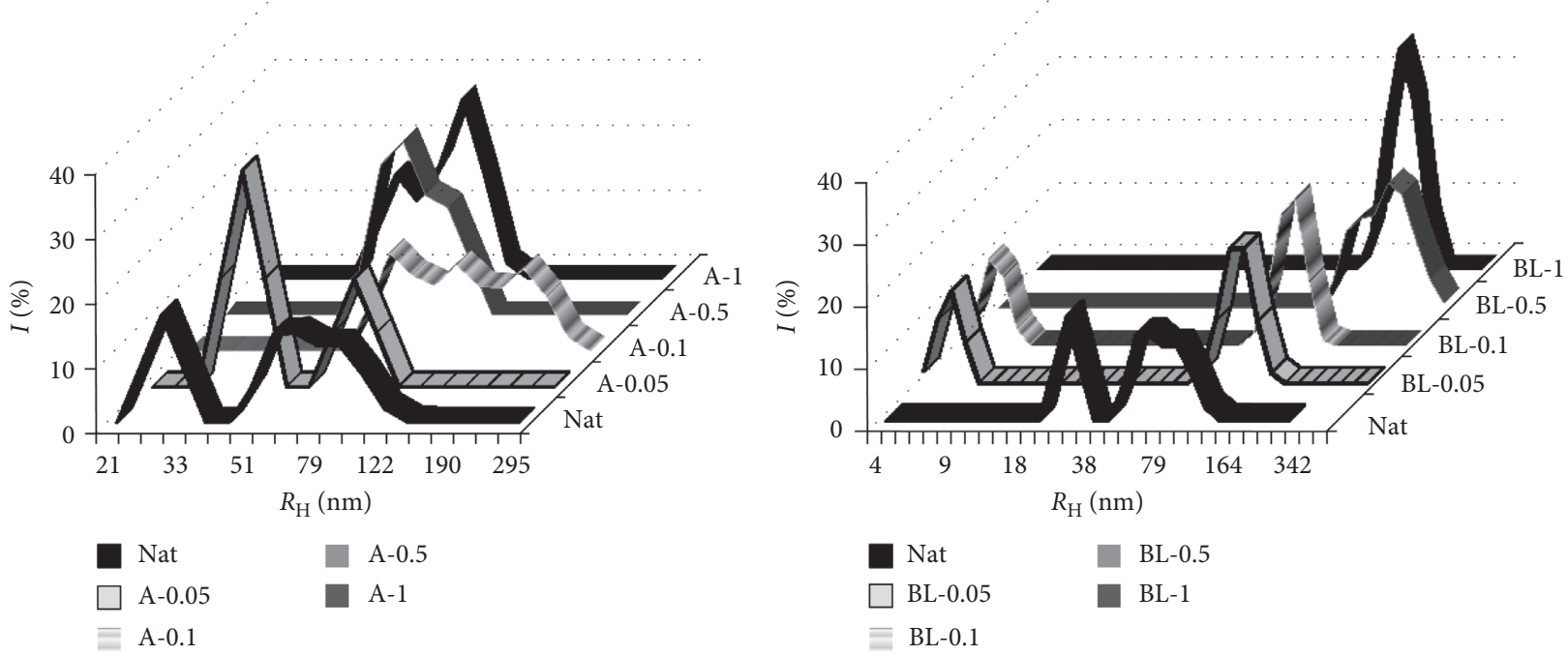

FIGURE 3: Distribution of the scattering intensity $I(\%)$ with respect to the hydrodynamic radius of the particles in $0.5 \mathrm{~g} \cdot \mathrm{l}^{-1}$ solution of starches in DMSO. Measurement temperature: $25^{\circ} \mathrm{C}$.

slightly lower, and the highest values of radii were 100 and $141 \mathrm{~nm}$, respectively (Figure 3).

Distribution of the hydrodynamic radii of the macromolecules of AM-0.1, AM-0.5, A-1, Bl-0.5 starches, and Bl-1 was monomodal. Particle radii, where the light scattering intensity peaks were observed are $76-263 \mathrm{~nm}$ in AM-0.1 starch, $50-115 \mathrm{~nm}$ in AM-0.5, 44-115 nm in AM-1, 138$479 \mathrm{~nm}$ in $\mathrm{Bl}-0.5$, and $138-240 \mathrm{~nm}$ in $\mathrm{Bl}-1$.

3.5. TG and DTA Characteristics. Heating of the starch is widely used in food industry and in manufacturing of starchbased products. Thermal degradation and thermal stability of starch being heated are the key problems in terms of both research and practice. Dehydration and degradation of starch molecules are two basic processes of the starch degradation mechanisms.

At the first stage (Table 4), the starch molecules lose their masses due to dehydration that was finished at the temperature of about $100^{\circ} \mathrm{C}$ for all samples (Figures $4(\mathrm{a})$ and $4(\mathrm{~b})$ ). This process is related to the endothermic peak on the DTA curve (Figures 4(c) and 4(d)). As the dehydration of starch samples was finished, each of them was stable up to the certain temperature: $290^{\circ} \mathrm{C}$ for native starch, $190^{\circ} \mathrm{C}$ for $\mathrm{AM}-0.05$ and $\mathrm{Bl}-0.05,200^{\circ} \mathrm{C}$ for $\mathrm{AM}-0.1$ and $\mathrm{Bl}-0.1,230^{\circ} \mathrm{C}$ for $\mathrm{AM}-0.5$, $250^{\circ} \mathrm{C}$ for $\mathrm{Bl}-0.5,270^{\circ} \mathrm{C}$ for $\mathrm{AM}-1$, and $280^{\circ} \mathrm{C}$ for $\mathrm{Bl}-1$.

The lower temperatures of the destruction of the samples of modified starches at the second stage are probably related to their partly destructed structure and lower molecular mass, compared to the native starch.

The temperature of ending of the second stage of the starch dehydration was different for all of the samples: $330^{\circ} \mathrm{C}$ for native starch, $350^{\circ} \mathrm{C}$ for $\mathrm{A}-0.05, \mathrm{Bl}-0.05$, and $\mathrm{A}-0.1,370^{\circ} \mathrm{C}$ for $\mathrm{Bl}-0.1,390^{\circ} \mathrm{C}$ for AM-0.5, Bl-0.5, and $\mathrm{Bl}-1$, and $430^{\circ} \mathrm{C}$ for $\mathrm{AM}-1$. The second stage of mass loss can be explained by the degradation of the organic substance with the relevant exothermic peak visible on the DTA curve. The second stage of chemical dehydration and
TABLE 4: Mass loss percentages of potato native and treatment starches, calculated by TGA.

\begin{tabular}{lcccc}
\hline Samples & $\begin{array}{c}\text { First } \\
\text { stage (\%) }\end{array}$ & $\begin{array}{c}\text { Second } \\
\text { stage (\%) }\end{array}$ & $\begin{array}{c}\text { Third } \\
\text { stage (\%) }\end{array}$ & $\begin{array}{c}\text { Residue } \\
(\%)\end{array}$ \\
\hline Native & 13.09 & 58.77 & 27.25 & 0.89 \\
AM- & 15.21 & 51.93 & 29.45 & 3.40 \\
0.05 & 15.03 & 50.31 & 31.64 & 2.02 \\
AM-0.1 & 17.54 & 47.54 & 34.78 & 0.14 \\
AM-0.5 & 17.50 & 57.67 & 24.66 & 0.17 \\
AM-1 & 14.26 & 52.9 & 32.72 & 0.01 \\
Bl-0.05 & 15.34 & 52.4 & 32.06 & 0.14 \\
Bl-0.1 & 15.98 & 50.55 & 33.11 & 0.34 \\
Bl-0.5 & 16.28 & 53.67 & 29.85 & 0.2 \\
Bl-1 & & & &
\end{tabular}

chemical degradation has higher values in modified starches than in the native starch. This effect of enzyme modification can be related to more aerated structures of starch kernels and to the deeper and stronger penetration of water molecules in the polymer structure. This causes a longer and gradual dehydration and a smoother course of the TG curve (mass loss).

The exothermic peak on the DTA curve is related to the heat energy released during the combustion of the starch derivatives. Whereas in native starch, the highest energy release peaks were at the level of 5 and $6 \mathrm{~W} / \mathrm{g}$ of starch; in the enzyme-modified, it exceeded $8 \mathrm{~W} / \mathrm{g}$ of starch. Thus, these starches contain the molecules of both simple and more complex structure compared to the native starch. This is confirmed by the temperatures of the beginning and the ending of the second stage of starch destruction, which are lower and higher than in the native starch, respectively. Further heating of relatively large conjugated structures, including aromatic structures formed at a temperature of about $600^{\circ} \mathrm{C}$, leads to the formation of amorphous carbon. As a result of the third stage of degradation, ash residues were formed. As a result of the enzyme 


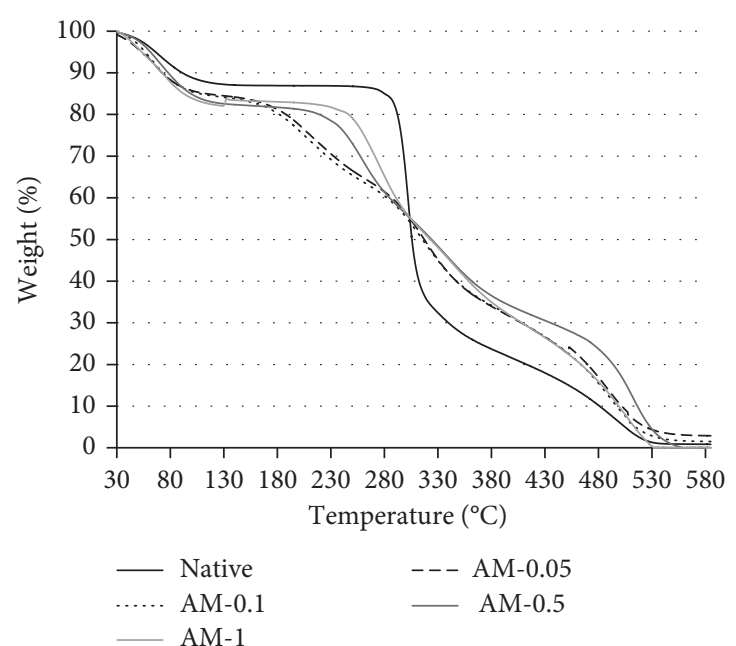

(a)

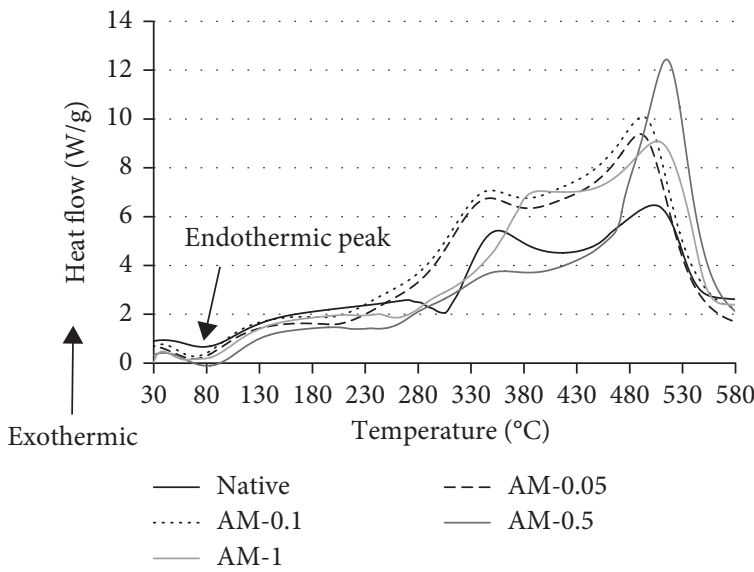

(c)

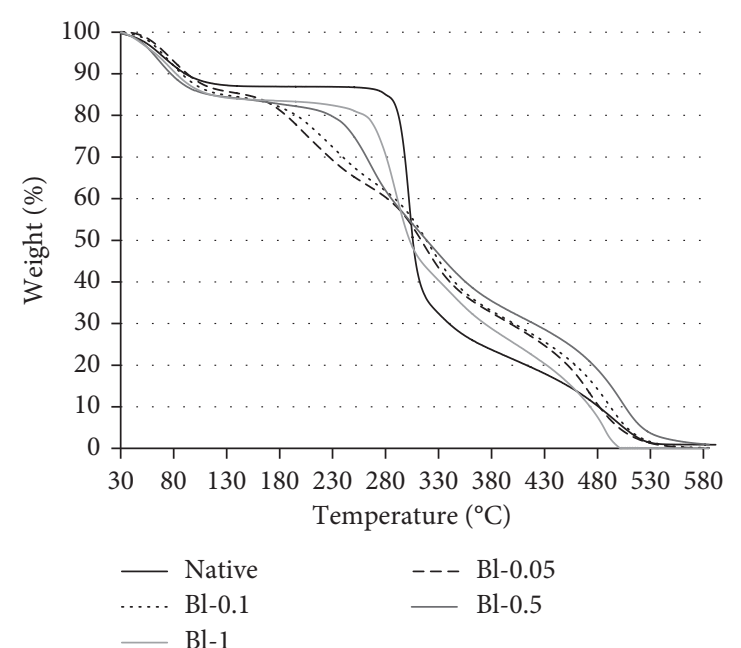

(b)

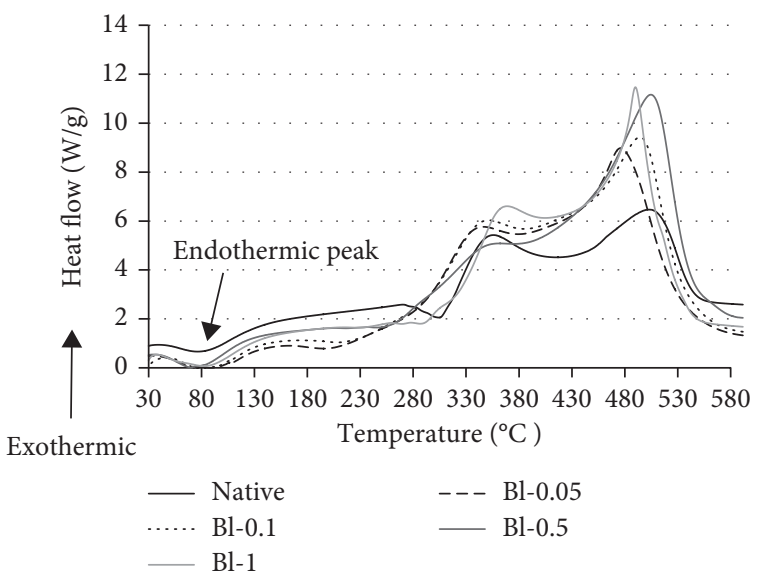

(d)

Figure 4: TGA $(\mathrm{a}, \mathrm{b})$ and DTA $(\mathrm{c}, \mathrm{d})$ curves of native and treated starches.

modification, the percentage of mass loss at temperatures above $500^{\circ} \mathrm{C}$ increased, which may indirectly indicate an increase in the share of high molecular weight polysaccharide residues (Table 4). This correlates with the results of the measurement of hydrodynamic radius of the particles, which indicates an increase in the proportion of larger starch particles after enzymatic processing (Figure 3).

Enzyme modification is becoming one of the most popular methods which allow obtaining a harmless starch with the predefined properties [19-22]. The combined results of the analysis of the percentage of amylose/amylopectin, the size of dynamic radii, and thermogravimetric characteristics have shown that the amylosubtilin treatment is basically related to the hydrolysis of the potato starch amylose fraction (Figures 3 and 4 and Table 2). It is natural that the hydrolysis process is more intensive for higher concentration of the enzyme involved in modification.

Modification with the Bacillus licheniformis amylase causes changes in the starch molecule sizes and the amylose/amylopectin ratio which provide evidence of both amylose fraction and amylopectin fraction. At the same time, when low doses of the enzyme are used, the amylopectin fraction exposes to more significant changes, and its percentage decreases. Bl-0.05 and Bl-0.1 starches contain smaller molecules of amylose and larger molecules of amylopectin compared to the native starch. The increase of the enzyme concentration during modification results in the elimination of small granules, while the amylopectin fraction of Bl-0.5 and Bl-1.0 starches turned out to be larger compared to the native starch. The increase of the amylopectin molecule sizes in starches $\mathrm{Bl}-0.5$ and $\mathrm{Bl}-1$ is probably related to the effect provided by the enzyme of a complex nature, with its aerating capability, internal bonds breaking, and change of the architecture of the granule structures. Moreover, it can be assumed that, as a result of hydrolyzing the endo-bonds of amylopectin, the amylopectin fraction is aerated easier in the DMSO medium.

The differences in the effects provided on the structure of potato starch granules by amylosubtilin and by the Bacillus licheniformis amylase are shown in SEM microimages (Figure 2). The effect of amylosubtilin leads to the occurrence of granules having uneven edges, notches, and grooves that becomes worse as the enzyme concentration grows. As to the Bacillus licheniformis amylase, it breaks the external 
layers that become rough, but the form of granules does not change for the low doses of the drug. Increasing the dose of this amylase results in gelatinizing of the granules; while the swelling and holes are visualized, this provides evidence of the starting breakage of the internal layers of the starch granules. We can make a conclusion that, with the identical amylase activity in amylosubtilin and the Bacillus licheniformis enzyme, their effects do not coincide, which can be determined by the minor activities of multienzyme preparations of low purification degree.

Partial processing with bacterial drugs enhances the solubility, which is important in terms of use of the starches in technologies that do not require critical temperatures. Enhancing the water-sorption activities of enzymatically modified potato starches is also important, which can be explained by both the increased dose of amylopectin and the changes in the architecture of starch granules. Lowering and smoothing the TGA profile, as well as reducing temperature ranges and gelatinization temperature, have shown that there were significant modifications in the internal granulated organization of the native and enzymatically modified starches. It is found that the temperature and structural properties of different starches are directly influenced by the presence of amylose/amylopectin [23].

\section{Conclusion}

Enzyme treatment can reduce the viscosity of potato starch, while increasing the WAC and its solubility at room temperature (WSI). The changes are due to morphological alterations, loosening of starch granules, respectively, an increase in the total area of contact. The most appropriate treatment with the enzyme Bacillus licheniformis in low doses, since the starch grains have a fine-cored structure, optimal for uniform penetration of water molecules with subsequent gelation.

The combination of functional, processing, thermal, and structural characteristics of the starches obtained from the modification shows their suitability for becoming materials for food systems' component that require the correction of their textural features. Such starches are promising for the techniques of correcting the structural and mechanical properties of low-fat fermented milk products, such as puddings or fat-free milkshakes. The use of low purification bacterial amylolytic preparations may be a cost-effective and efficient method of obtaining starches having modified properties without any nonbiological components or affected by high temperatures or pressures.

\section{Data Availability}

The data used to support the findings of this study are available from the corresponding author upon request.

\section{Conflicts of Interest}

The authors declare that there are no conflicts of interest regarding the publication of this paper.

\section{Acknowledgments}

This work was financially supported by the Youth Scientific Grants and Awards of the Republic of Tatarstan (Russia) (No. 10-79-xG/2017) and the Program of Competitive Growth of Kazan Federal University.

\section{References}

[1] P. Roger, R. A. Bello-Perez, and P. Collona, "Contribution of amylose and amylopectin to the light scattering behavior of starches in aqueous solution," Polymer, vol. 40, no. 25, pp. 6897-6909, 1999.

[2] S. Radosta, M. Haberer, and W. Vorwerg, "Molecular characteristics of amylose and starch in dimethyl sulfoxide," Biomacromolecules, vol. 2, no. 3, pp. 970-978, 2001.

[3] J. N. Bemiller, "Starch modification: challenges and prospects," Starch-Stärke, vol. 49, no. 4, pp. 127-131, 1997.

[4] O. B. Wurzburg, "Modified starches," in Food Polysaccharides and Their Applications, A. M. Stephen, Ed., pp. 83-85, Marcel Dekker, New York, NY, USA, 1995.

[5] M. H. Madsen and D. H. Christensen, "Change in viscosity properties of potato starch during growth," Starch/Starke, vol. 48, no. 7-8, pp. 245-249, 1996.

[6] A. Buleon, P. Colonna, V. Planchot, and S. Ball, "Starch granules: structure and biosynthesis," International Journal of Biological Macromolecules, vol. 23, no. 2, pp. 85-112, 1998.

[7] J. L. Jane, T. Kasemsuwan, S. Leas, H. Zobel, and J. F. Robyt, "Anthology of starch granule morphology by scanning electron microscopy," Starch-Stärke, vol. 46, no. 4, pp. 121-129, 1994.

[8] R. Amini Sarteshnizi, H. Hosseini, A. Mousavi Khaneghah, and N. Karimi, "A review on application of hydrocolloids in meat and poultry products," International Food Research Journal, vol. 22, no. 3, pp. 872-887, 2015.

[9] R. Hoover, "Composition, molecular structure, and physicochemical properties of tuber and root starches: a review," Carbohydrate Polymers, vol. 45, no. 3, pp. 253-267, 2001.

[10] L. Kaur, J. Singh, O. J. McCarthy, and H. Singh, "Physicochemical, rheological and structural properties of fractioned potato starches," Journal of Food Engineering, vol. 82, no. 3, pp. 383-394, 2007.

[11] N. Singh and L. Kaur, "Morphological, thermal, rheological and retrogradation properties of potato starch fractions varying in granule size," Journal of the Science of Food and Agriculture, vol. 84, no. 10, pp. 1241-1252, 2004.

[12] Z. Chen, H. A. Schols, and A. G. J. Voragen, "Starch granule size strongly determines starch noodle processing and noodle quality," Journal of Food Science, vol. 68, no. 5, pp. 1584-1589, 2003.

[13] J. Singh and N. Singh, "Studies on the morphological, thermal and rheological properties of starch from some Indian potato cultivars," Food Chemistry, vol. 75, no. 1, pp. 67-77, 2001.

[14] P. C. Williams, F. D. Kuzina, and I. Hlynka, "A rapid colourimetric procedure for estimating the amylose content of starches and starch," Cereal Chemistry, vol. 47, no. 4, pp. 411-413, 1970.

[15] M. Bradford, "A rapid and sensitive method for the quantitation of microgram quantities of protein utilizing the principle of protein-dye binding," Analytical Biochemistry, vol. 72, no. 1-2, pp. 248-254, 1976.

[16] G. L. Miller, "Use of dinitrosalycylic acid reagent for determination of reducing sugar," Analytical Chemistry, vol. 31, no. 3, pp. 426-428, 1959. 
[17] M. O. Omojola, Y. O. Akinkunmi, K. O. Olufunsho, H. O. Egharevba, and E. O. Martins, "Isolation and physicochemical characterization of cola starch," African Journal of Food, Agriculture, Nutrition and Development, vol. 10, no. 7, pp. 2884-2900, 2010.

[18] A. A. Attama, P. O. Nnamani, I. K. Mbonu, and M. U. Adiku, "Effect of hypochlorite oxidation on the physicochemical properties of gladiolus starch," Journal of Pharmaceutical and Allied Sciences, vol. 1, no. 1, pp. 28-35, 2003.

[19] M. G. Casarrubias-Castillo, B. R. Hamaker, S. L. RodriguezAmbriz, and L. A. Bello-Perez, "Physicochemical, structural, and digestibility properties of enzymatic modified plantain and mango starches," Starch/Starke, vol. 64, no. 4, pp. 304312, 2012.

[20] M. M. Kasprzak, H. N. Lærke, F. H. Larsen, K. E. B. Knudsen, S. Pedersen, and A. S. Jørgensen, "Effect of enzymatic treatment of different starch sources on the in vitro rate and extent of starch digestion," International Journal of Molecular Sciences, vol. 13, no. 1, pp. 929-942, 2012.

[21] B.-S. Kim, H.-S. Kim, and S.-H. Yoo, "Characterization of enzymatically-modified rice and barley starches with amylosucrase at scale-up production," Carbohydrate Polymers, vol. 125, pp. 61-68, 2015.

[22] S. H. Park, Y. Na, S. D. Kim, J. Kang, and K.-H. Park, "Properties and applications of starch modifying enzymes for use in the baking industry," Food Science and Biotechnology, vol. 27, no. 2, pp. 299-312, 2018.

[23] M. Schirmer, A. Höchstötter, M. Jekle, E. Arendt, and T. Becker, "Physicochemical and morphological characterization of different starches with variable amylose/ amylopectin ratio," Food Hydrocolloids, vol. 32, no. 1, pp. 52-63, 2013. 

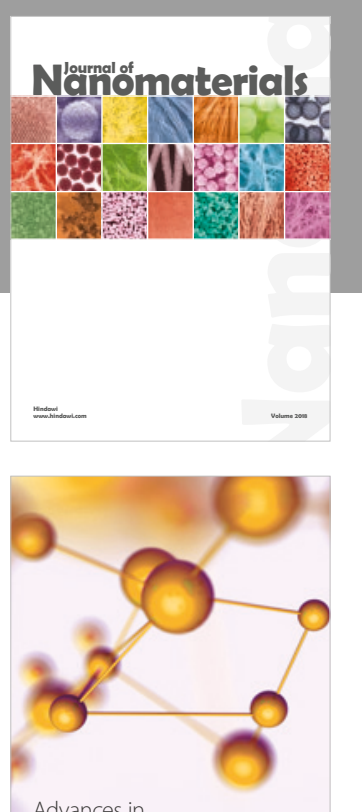

Physical Chemistry
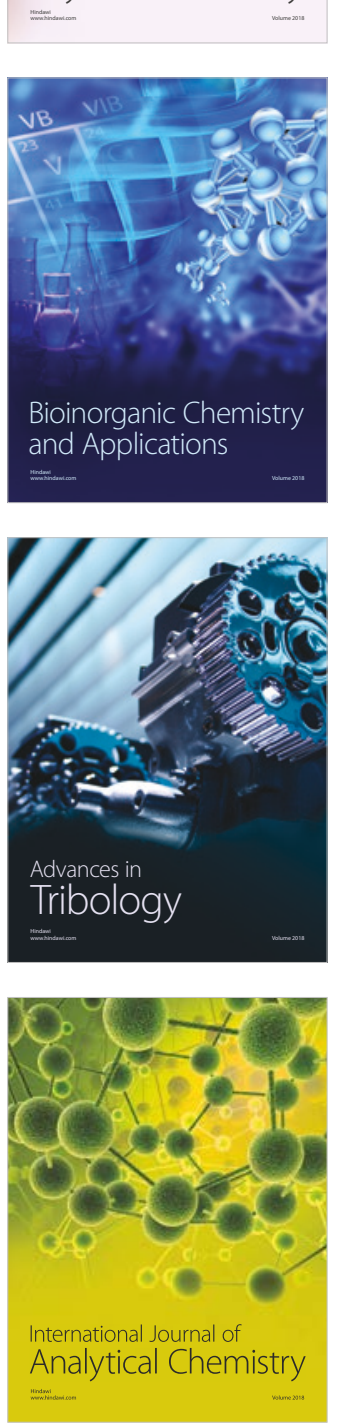

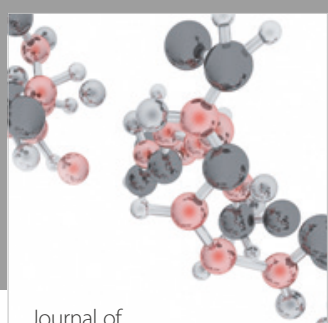

Analytical Methods

in Chemistry

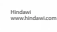

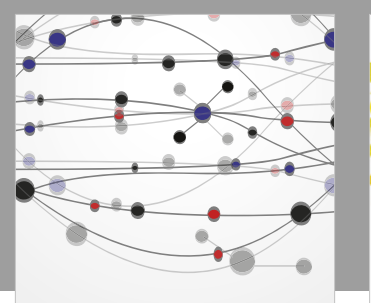

The Scientific World Journal

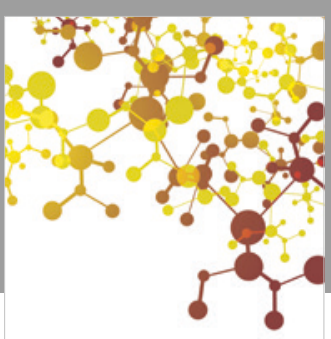

Journal of

Applied Chemistry
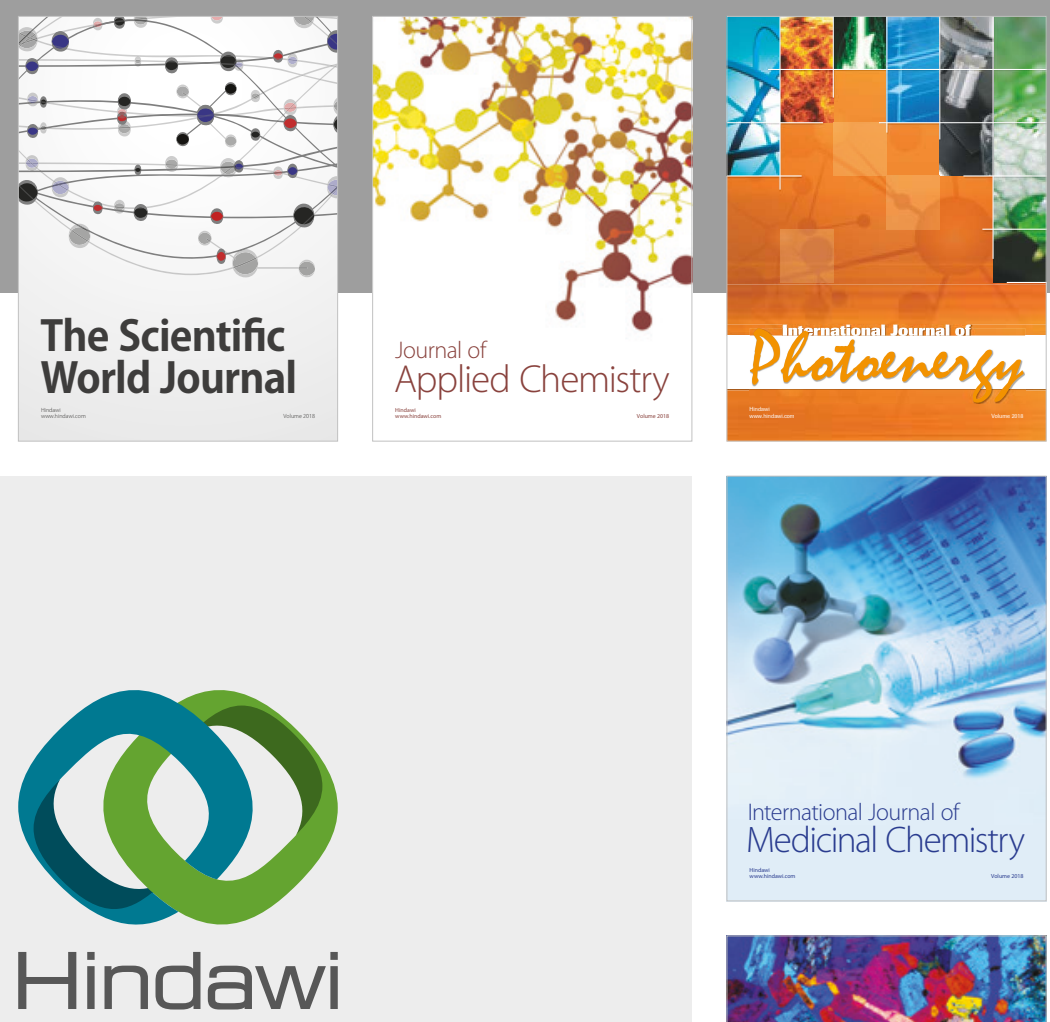

Submit your manuscripts at

www.hindawi.com
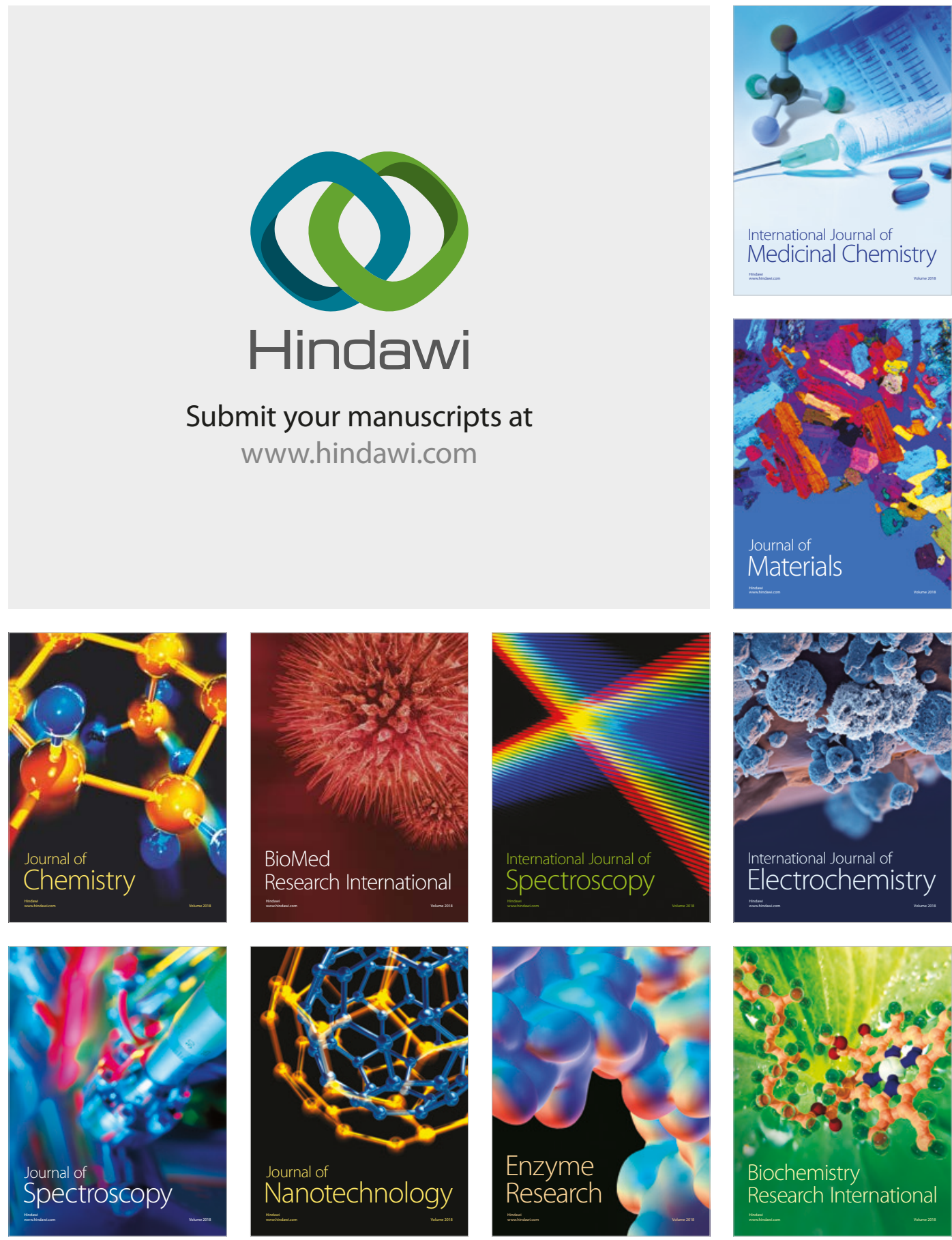
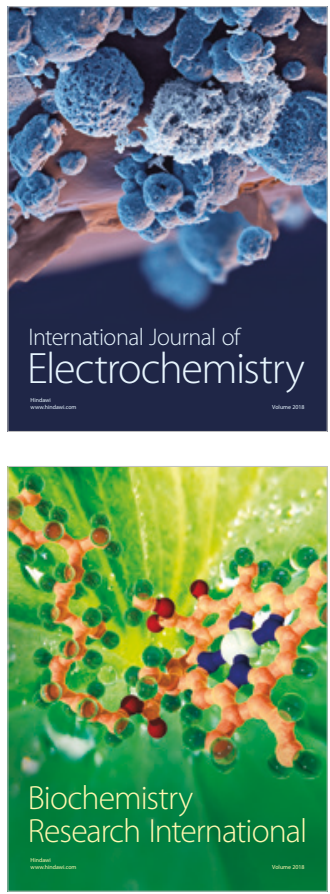